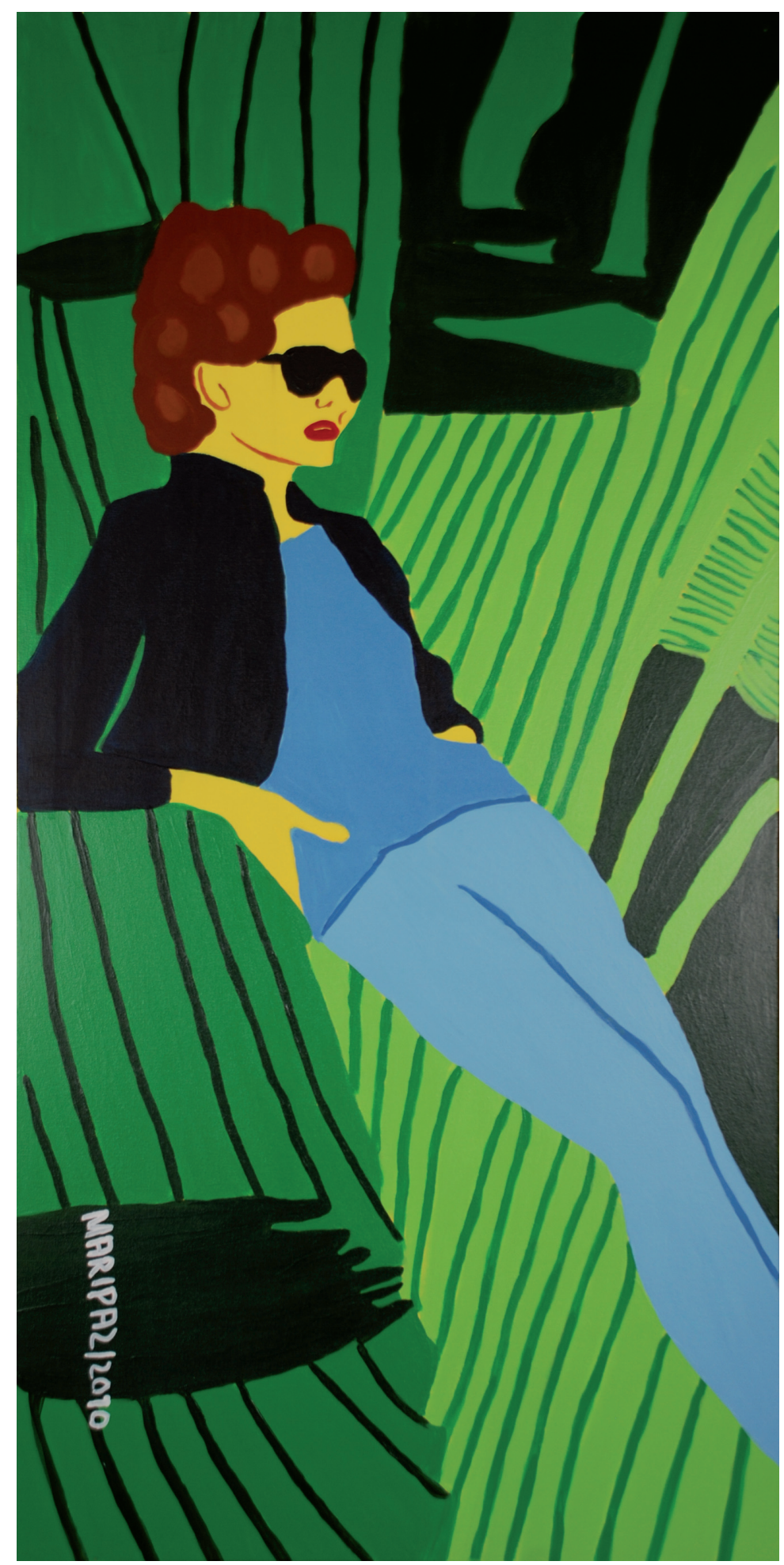

Serie Ellas. Ellas 6

Acrílico sobre lienzo. 2010. 1,20 x 0,60 mts.

Maripaz Jaramillo 


\section{Restauración ecológica del campus de la Institución Universitaria Politécnico Grancolombiano}

Fecha de recepción: 10 de marzo de 2011 - Aprobación: 6 de abril de 2011

\section{Clemencia Camacho Delgado - Ana Mariá Mejía de Michelsen}

\section{Resumen}

En el artículo se describe el proceso de restauración ecológica del Campus del Politécnico Grancolombiano ubicado en los Cerros Orientales de Bogotá. Este proyecto hace parte del Sistema de Gestion Ambiental en el programa Manejo de los Jardines del Campus, cuyo objetivo es fortalecer la gestión ambiental relacionada con la siembra de árboles nativos y el enriquecimiento del suelo. A su vez, el propósito de planear y ejecutar las acciones necesarias para restablecer el equilibrio natural y avanzar hacia una restauración ecológica del predio, se planteó como un proyecto piloto de interés para la Corporación Autónoma Regional de Cundinamarca CAR, dada la importancia de este proceso y su seguimiento para los Cerros que circundan la ciudad.

Adicionalmente, en la metodología se establecieron las características de los aspectos físicos y bióticos del Campus, se realizó un inventario forestal y se llevaron a cabo los diseños y ejecuciones de los planes de manejo y aprovechamiento forestal, de restauración ecológica para las áreas intervenidas y de manejo y monitoreo posteriores. Así, los resultados están determinados por el mediano y largo plazo de acuerdo con el plan y ejecución de manejo y monitoreo, contemplado como parte de la mejora continua en el Sistema de Gestion Ambiental. Sin embargo, el artículo hace referencia a los resultados obtenidos en el contexto de la comunidad académica como participe y acompañadora del proceso de transformación del Campus y de los factores de cambio ambiental alcanzados hasta el momento.

\section{Abstract}

The article describes the process of ecological restoration of the campus of Politécnico Grancolombiano, located in the eastern hills of Bogota. This project is part of the Environmental Management System in the program Management of the Campus Gardens, which aims to strengthen the environmental management related to the planting of native trees and soil enrichment. At the same time, the purpose of planning and executing the necessary actions to restore the natural balance and move towards the ecological restoration of the campus was proposed as a pilot project of interest to the Autonomous Regional Corporation of Cundinamarca CAR, given the importance this process and its follow-up have for the hills surrounding the city.

In addition, within the methodology, the characteristics of the physical and biotic aspects of the campus were established. Also, a forest inventory was carried out as well as the designs and executions of forest management and exploitation plans along with those for the ecological restoration of the areas treated and their subsequent monitoring. In summary, the results are determined by medium and long terms, according to the plan and execution of the 
management and monitoring included as part of the continuous improvement in the Environmental Management System. However, the article refers to the results obtained in the context of the academic community that participates and experiences the process of transforming the Campus and the factors of environmental change achieved so far.

\section{Introducción}

La Fundación Universitaria Politécnico Grancolombiano está ubicada en los Cerros Orientales de Bogotá a $2.767 \mathrm{msnm}$, hecho que ha generado en sus directivas un compromiso como generadores de un cambio social dirigido hacia la responsabilidad y uso adecuado del capital natural, con la implementación de un sistema de manejo ambiental, de campañas de sensibilización, y con la inclusión en los programas académicos de la dimensión ambiental.

Los Cerros Orientales, son considerados como uno de los principales ecosistemas estratégicos de Bogotá. Son un territorio heterogéneo en formas de uso y ocupación, rico en

\section{Reseña de autores \\ Clemencia Camacho Delgado (Colombia) \\ Politécnico Grancolombiano \\ ccamacho@poligran.edu.co \\ Bióloga y MSc. de la Pontificia Universidad Javeriana, con especialización en Gestión Ambiental de la Universidad Externado de Colombia. Actualmente es la Directora de Alianzas Académicas Internacionales del Politécnico Grancolombiano, autora de varios artí- culos académicos y líder investigadora de la Comunidad Latinoamericana Urdimbre Educación e Investigación.}

\section{Ana María Mejía De Michelsen (Colombia)}

Politécnico Grancolombiano

Experta en diseño y administración de jardines. Ha obtenido numerosos reconocimientos en el área de la Orquideología por parte de asociaciones como la Asociación Bogotana de Orquideología (ABO). Fue Presidente de la $\mathrm{ABO}$, directora de exposiciones nacionales de orquídeas y dicta cursos de orquideas en el Jardín Botánico de Bogotá, Jose Celestino Mutis. Consultora y asesora del proceso de restauración ecológica con especies nativas del campus del Politécnico Grancolombiano y tiene a su cargo la dirección de los jardines de la Institución.

\section{Palabras clave}

Medio ambiente, restauración ecológica, Gestión ambiental

\section{Keywords}

Environment, ecologic restoration, environmental management

valores ecológicos y paisajísticos, que poseen diversidad de especies de flora y fauna, con unos aportes importantes como regulador del acuífero de la sabana, del clima y la depuración del aire, de la protección y estabilización de los suelos (Wiesner \& Andrade, 2004).

Consciente de su entorno y preocupado por brindar el mejor manejo posible de los recursos a su cargo, el Rector y las directivas del Politécnico Grancolombiano han visto con preocupación cómo las áreas boscosas dentro del Campus se deterioran progresivamente y cómo la posibilidad del volcamiento de los árboles de eucalipto viejos y enfermos se ha acrecentado. Esto deriva en una amenaza no sólo para la comunidad universitaria dentro de los predios de su espacio, sino también para las comunidades vecinas. Así mismo, los problemas de erosión y pérdida de suelos han llevado a buscar formas de lograr su recuperación y mantenimiento.

Teniendo en cuenta los factores anteriores y con base en la experiencia de los últimos años, la Dirección de Operaciones a través del Departamento de Infraestructura y Soporte identificó la urgente necesidad de realizar un plan de mejoramiento ambiental dentro de sus predios, con un manejo forestal que incluyera la eliminación de los árboles de alto riesgo en busca de restablecer procesos de conservación y equilibrio natural y de esta manera avanzar hacia una restauración ecológica.

Consecuentemente con la localización de la Institución, los procesos han sido desarrollados conjuntamente en proyectos 
de interés, de acuerdo con la Corporación Autónoma Regional de Cundinamarca CAR, y dando cumplimiento a los requerimientos de esta entidad pública.

\section{Antecedentes}

La preocupación por el estado de conservación de los Cerros Orientales ha motivado una serie de estudios desarrollados por los organismos de control ambiental del Distrito y por varias ONG's. En consecuencia, en la localidad de Chapinero que corresponde al área del Politécnico Grancolombiano, se han realizado estudios sobre los aspectos sociales que incluyen el desarrollo rural y ambiental. Estos diagnósticos, permiten establecer la evolución histórica desde actividades netamente campesinas hacia actividades industriales y de explotación de los recursos naturales, además de los impactos generados sobre el medio ambiente (D.A.M.A., 2000).

De modo paralelo, estudios realizados por la Contraloría de Bogotá (2000) y por la CAR (Herrán, 2001) muestran la relación que han tenido las comunidades asentadas en los Cerros Orientales con los diferentes niveles de explotación de recursos.

Así mismo, existe un inventario de flora y fauna que establece el estado de los ecosistemas altoandinos y que muestra el verdadero deterioro presentado en esta zona de la ciudad en los últimos años realizado por la Fundación Estación Bachaqueros (Fundación Estación Biológica Bachaqueros-D.A.M.A., 1998).

Uno de los trabajos más completos respecto al inventario de flora y fauna fue desarrollado por el Consorcio Gerenciar y el D.A.M.A. (Consorcio Gerenciar- D.A.M.A., 2000). En él se presenta un listado completo de las especies vegetales y animales encontradas en los Cerros Orientales que muestra el desplazamiento de especies nativas por la introducción de especies foráneas y el impacto que esto le genera al ecosistema.

A su vez, el Politécnico Grancolombiano desde 1981 viene contribuyendo con un estudio sobre el estado de la cuenca hidrográfica de Las Delicias, a la cual pertenece, en aras de plantear soluciones a los problemas de degradación (Proyecto de Desarrollo Ltda, 1981) (Informe Visita CAR, 1981). Allí se propuso un manejo integral de la cuenca incluyendo un programa de vigilancia para evitar la destrucción durante los fines de semana por parte de los visitantes y la implementación de otro correspondiente a la reforestación y recreación, encaminado no sólo a recuperar la degradación de los suelos y la pérdida de recursos sino a educar y generar una conciencia ciudadana.

Este estudio se ha venido complementando con una serie de proyectos de investigación que se iniciaron con el Diagnóstico Ambiental de la Flora (Camacho, Quintero, \& Muñoz, 2004) en el que se relaciona la flora existente en el Campus tanto nativa como exótica y su correspondencia con los suelos, la revisión ambiental (Avendaño, Camacho, \& Castro, 2004), y la propuesta de Implementación de un Sistema de Gestión Ambiental (Camacho, 2005 y Camacho, 2007). Estos estudios muestran los serios problemas de los árboles de eucaliptos en el Campus, el avanzado estado de enfermedad, la edad y los peligros que implican para la comunidad.

Teniendo en cuenta los anteriores referentes, el Politécnico Grancolombiano inició en el año 2000 una solicitud ante el Departamento Técnico Administrativo del Medio Ambiente D.A.M.A., para la tala de árboles de Eucalipto y el remplazo de estos por árboles nativos. Con base en el concepto técnico No. 12444 emitido por el D.A.M.A. se otorgó la tala de 50 árboles y autorizó plantar 300 nativos con un mínimo de 1,5 m de altura (Acto Administrativo, 2001). Posteriormente, en el 2007 el Politécnico 
Los Cerros

Orientales tutelares de Bogotá D.C., denominados el Telón de Fondo de la Capital, han sido objeto de múltiples intervenciones con efectos sobre su conservación y preservación, muchos de ellos ocasionados como resultado depoliticas y normas del orden nacional, regional y local; de actuaciones de particulares, y de la falta de mecanismos para ejercer su controly vigilancia.
Grancolombiano solicitó una visita a la CAR por estar en su jurisdicción. La entidad realizó un inventario dando como resultado un diagnóstico de enfermedad, e inclinación de árboles y en mayo de 2010 hace una nueva inspección para constatar el estado de alto riesgo de volcamiento de los árboles.

Finalmente, la CAR otorgó el permiso 026 del 4 agosto de 2010 para la tala de 420 árboles de Eucalipto siguiendo el principio de precaución (CAR, 2010). El interés de las dos entidades en la recuperación ambiental de los cerros y la autorización otorgada por la CAR dio pie a proponer y desarrollar el proyecto piloto que muestre procesos de restauración ecológica relacionada con la siembra de árboles de especies nativas y la recuperación de suelos.

\section{Marco de referencia}

Los Cerros Orientales tutelares de Bogotá D.C., denominados el Telón de Fondo de la Capital, han sido objeto de múltiples intervenciones con efectos sobre su conservación y preservación, muchos de ellos ocasionados como resultado de políticas y normas del orden nacional, regional y local; de actuaciones de particulares, y de la falta de mecanismos para ejercer su control y vigilancia. Simultáneamente, se han expedido un sinnúmero de reglamentaciones por parte de las entidades ambientales de las diferentes órdenes orientadas a proteger su valor ambiental y paisajístico, a regular los usos, a mitigar los efectos de la ocupación y a restringir la continua utilización de recursos del subsuelo. Pese a dichas normas y, quizás como consecuencia de ellas, y de la diversidad de entidades con actuaciones y competencias en esta importante área de Bogotá se han generado y subsisten conflictos de intereses que se evidencian en el deterioro de los Cerros mismos (Plan de Manejo Ambiental Audiencia CAR, 2006).
Sin embargo, a pesar de existir una medida impuesta por el Tribunal Administrativo de Cundinamarca de no otorgar permisos ni licencias ambientales, dentro de estas áreas consideradas de reserva forestal, la Corporación Autónoma Regional de Cundinamarca, CAR, considera, el principio de precaución, que faculta a la autoridad ambiental y a los particulares para incentivar la implementación de prácticas silviculturales apropiadas y acordes con los requerimientos ecológicos a fin de proteger los derechos fundamentales de la vida y de vivienda digna de la comunidad estudiantil, sobre los cuales existe una amenaza muy alta de volcamiento de los árboles de la especie Eucalipto (Eucalyptus globulus).

En comunión con lo anterior, este principio se dirige igualmente a evitar la degradación del medio ambiente en el recurso suelo, debido a la demanda hídrica que genera la plantación, la cual aumenta los procesos erosivos que se evidencian en las grietas y las cárcavas presentes, incrementando el arrastre de sedimentos por lavado superficial que puedan afectar a la zona y a la comunidad por fenómenos de remoción en masa.

El plan de aprovechamiento forestal, formulado para el área de estudio en el Campus del Politécnico Grancolombiano, está amparado por los criterios e indicadores para el aprovechamiento sostenible de los bosques naturales promulgados por el Ministerio del Medio Ambiente en la (Ley 99 de 1993) y regido bajo la Legislación Ambiental Nacional a través de:

\section{Decreto Lev 2811 de 1974}

A través del cual se reglamenta el Código Nacional de los Recursos Naturales Renovables (RNR) y no renovables y de protección al medio ambiente. 
(El ambiente es patrimonio común, el Estado y los particulares deben participar en su preservación y manejo. Regula el manejo de los RnR, la defensa del ambiente y sus elementos).

Decreto 1791 de 1996

Regula el régimen de aprovechamiento forestal, en virtud del cual se determinan, las actividades de administración pública y de los particulares; respecto del uso, manejo, aprovechamiento y conservación de los bosques y de la flora silvestre, con el fin de lograr su desarrollo sostenible.

\section{Acuerdo 028 del 30 de noviembre de 2004}

Por el cual se regula el uso, manejo, aprovechamiento de los bosques y la flora silvestre y la movilización de sus productos en la jurisdicción de la Corporación Autónoma Regional de Cundinamarca-CAR.

\section{Resolución CAR 1141 de 2006}

Determina a través del Artículo 20, numeral 3 , que quedan sujetas a licencias previas, permisos, concesiones o autorizaciones, dentro de la reserva forestal protectora declarada por la Resolución 76 de 1977, la ejecución de diferentes actividades, dentro de las cuales resalta:

- La investigación científica con especies de la biodiversidad existente en la reserva forestal.

- El aprovechamiento de árboles aislados, cuando se encuentren caídos o muertos por causas naturales, o para el control de emergencias fitosanitarias y la prevención de riesgos.

- El aprovechamiento doméstico de bosque plantado, siempre y cuando se compense con especies de bosque nativo.

\section{Autorización N N 026 del 4 de agosto del 2010 :}

Otorgada por la Corporación Autónoma

Regional de Cundinamarca CAR, con la cual se autoriza el aprovechamiento para 420 árboles de alto riesgo dentro de las instalaciones de la universidad Politécnico Grancolombiano.

\section{Características físico - bióticas del área de estudio Ubicación del terreno}

El Campus, está ubicado en la localidad № 2 de Chapinero, entre las coordenadas 1004916 Long Este y 1002577 Lat. Norte, altitud de los $2.729 \mathrm{msnm}$, con un área de aproximadamente 10 has.

Colinda con:

Al Oriente. Cerros Orientales de Bogotá

Al Occidente. Barrios correspondientes a Chapinero Alto

Al Norte. La Quebrada Las Delicias

Al Sur. Barrio Pardo Rubio

Hidrografía

El terreno se encuentra delimitado por una corriente hídrica que bordea la propiedad, perteneciente a la cuenca hidrográfica del río Bogotá y a la subcuenca de la Quebrada Las Delicias en los Cerros Orientales de la ciudad.

Dicha corriente es de segundo orden y carácter permanente, la cual limita con el predio hacia el norte, en sentido oriente occidente. La Quebrada Las Delicias resume la escorrentía correspondiente a los periodos de lluvia de los drenajes provenientes de cotas más altas, por la parte Nororiental del predio, punto a partir del cual lo bordea.

\section{Clima}

Posee un clima frío subhúmedo, con tendencia a ser más seco en el sur y sureste. Según la base de datos de más de 30 años, se calcula la temperatura media multianual en $14,2^{\circ} \mathrm{C}$, siendo la más alta $25,2^{\circ} \mathrm{C}$ y la mínima $-1,8^{\circ} \mathrm{C}$, con variaciones inferiores a un grado y con ligera tendencia a un régimen bimodal, con promedios levemente más altos en los meses 
de marzo a junio y noviembre (D.A.M.A., 1994)

La humedad relativa del aire de 86 a $87 \%$ en los meses lluviosos y de 79 a $81 \%$ en los meses secos. El régimen de lluvias se encuentra determinado por el paso de la zona de convergencia intertropical lo que, sumado a la orografía del sector, estimula la caída entre 1.027 y $1.089 \mathrm{~mm}$, disminuyendo en sentido oriente-occidente (D.A.M.A., 1994).

\section{Orografía}

Los Cerros Orientales están ubicados en el Anticlinal Bogotá. Sus flancos están conformados por areniscas de la Formación Guadalupe Superior y, la parte central, por material de la Formación Guadalupe Inferior. En algunas zonas de los Cerros Orientales es posible observar material de la formación Guaduas.

Edafológicamente el Campus del Politécnico Grancolombiano tiene su basamento en dos de las formaciones anteriormente mencionadas. La parte superior, desde la línea de conducción de 115 voltios hacia el oriente, pertenece a la formación Guadalupe Superior, mientras que el resto de la universidad está sobre la Formación Guaduas (Proyecto de Desarrollo Ltda, 1981).

Los suelos se caracterizan por depósitos de cenizas volcánicas sobre un sustrato de areniscas cuarcíticas. Se presentan valles jóvenes cubiertos por cenizas volcánicas originando un modelado plano a ondulado (Proyecto de Desarrollo Ltda, 1981).

\section{Clases agrológicas}

La Caracterización agrológica general de la zona de estudio referenciada de los Cerros Orientales de Bogotá, corresponde a la Clase Agrológica IV, la cual pertenece a suelos que se caracterizan por ser fuertemente inclinados a fuertemente ondulados, con pendien- tes que oscilan entre el 12 al 35\%. La erosión es ligera hasta el $40 \%$, moderada hasta el $20 \%$ y severa hasta el $10 \%$.

La profundidad efectiva va de muy superficial hasta muy profunda; con un gradiente de pedregosidad, el cual oscila sin piedras hasta pendientes del $12 \%$ y pedregoso en pendientes del 12 al 35\%, con una salinidad hasta un $40 \%$ en suelos salinos sódicos (Plan de Manejo Ambiental Audiencia CAR, 2006).

En el área de estudio se encuentran suelos con relieve plano o moderadamente inclinado a ondulados, con pendientes inferiores al $12 \%$, sin erosión o con erosión ligera en un máximo de $20 \%$ del área, moderadamente profundos a muy profundos, con un gradiente de pedregosidad bajo, que no imposibilitan las labores de la maquinaria. Los drenajes son naturales de bueno a moderado o imperfecto. Las inundaciones se presentan ocasionalmente, de muy corta duración en inviernos rigurosos y no mayores de 1 a 2 días, sin producir daños de consideración. La retención de humedad es muy alta a mediana, la permeabilidad moderadamente lenta, moderadamente rápida o rápida, y el nivel de fertilidad es moderado.

\section{Uso del suelo}

Antes de la Colonia, los cerros estuvieron cubiertos por vegetación nativa como raque, encenillo, mortiño, canelo, romero, aliso, nogales y varios familiares del sietecueros como el angelito y arbustos parientes del pegamosco entre muchos. Los musgos y los líquenes al igual que las orquídeas son parte integral de estos ecosistemas; ellos aportan el color y las texturas propias del bosque nativo (Bartholomäus, Rosa, Santos, Acero, \& Moosbrugger, 1998).

Con el paso del tiempo, la alteración de los ecosistemas se fue ampliando en la medida en que esta zona fue explotada por las comunida- 
des. En la actualidad, la cobertura vegetal de los Cerros Orientales se caracteriza por presentar un predominio de matorrales, rastrojos, bosques y plantaciones forestales, con una menor proporción de pastizales y cultivos. Los altos niveles de intervención y explotación de sus recursos han llevado a que el área cubierta por bosques nativos representen sólo el 6.03\% del área total de los cerros, mientras que las plantaciones forestales de especies introducidas, tales como el Eucalipto (Eucalyptus globulus), pino pátula (Pinus patula), pino monterrey (Pinus radiata), acacia amarilla (Acacia decurrens), cubren casi el 12\% del área total (Consorcio Gerenciar- D.A.M.A., 2000)

En la actualidad el terreno de estudio se encuentra con cobertura de plantación de Eucalyptus globulus. Su uso potencial está dado como zona de reserva forestal protectora zps Forestal, áreas con potencial para establecer plantaciones forestales productoras y protectoras productoras con el uso de especies nativas y/o introducidas. De igual manera, hacen parte de esta categoría las áreas con cobertura de bosque natural, guadua, caña brava y/o especies afines, en los cuales es posible desarrollar prácticas de aprovechamiento selectivo o por el sistema de entresaca, o la obtención de productos secundarios con criterios de sostenibilidad; las cuales podrán estar dispersas en las zonas de producción agrícola y agroforestal.

\section{Historia del Campus'}

En el diagnóstico local, con Participación Social Localidad de Chapinero, los primeros datos reportados sobre los predios donde se encuentra la universidad se remontan a la Hacienda Barro Colorado, propiedad de Enrique Pardo Roche, quien, al fallecer en 1922, reparte las 346 Has entre sus hijos
(Alcaldia Local de Chapinero, 2001). A los hijos varones les correspondió la zona que va desde la Carrera 7a hasta la cuchilla del cerro, incluyendo los antiguos páramos de San Luis y San Cristóbal.

A partir de entonces, en las propiedades de los hermanos Pardo Rubio se lleva a cabo una intensa explotación de los recursos encontrados en esa área, especialmente el barro colorado, un tipo de arcilla usado en la fabricación del ladrillo en los chircales. Las utilidades que esta actividad les generó, llevó a que ambos hermanos construyeran hornos para la fabricación de ladrillos, a finales de 1928 (Alcaldia Local de Chapinero, 2001). La introducción de esta explotación minera convirtió a esta parte de los cerros en la despensa de la industria de la construcción de la época, pues de ella se extraía piedra, carbón, arena y madera.

Además de los hermanos Pardo Rubio, la empresa Cementos Samper hacía uso de los recursos de la zona para abastecer la central de mezclas, ubicada en lo que hoy es la Pontificia Universidad Javeriana. Fue tal el impacto causado por este tipo de actividades que el área de los cerros se fue degradando visiblemente, evidenciando graves procesos de erosión que se pueden apreciar en aerografías del año 1938 (IGAC, 1938) y comparar con aerofotografias 1998 (IGAC, 1998) en las que ya aparecen las plantaciones de árboles de eucaliptos y pinos. Inclusive, Cementos Samper se vio obligada a trasladar su planta al norte de Usaquén por los problemas que la explotación de las canteras con dinamita causaba a las vías de la zona (Alcaldía Local de Chapinero, 2001)

A finales de los años cuarenta y comienzos de los años cincuenta, la situación cambia

1. Camacho, Quintero, \& Muñoz. Diagnóstico del Campus de la Institución Universitaria Politécnico Grancolombiano, 2004. 
radicalmente. La explotación minera ya no es rentable y los hermanos Pardo Rubio se ven obligados a vender su terreno, iniciándose un fuerte proceso de urbanización. Así nacen los barrios Pardo Rubio, en honor a los antiguos dueños de las tierras, San Martín de Porres y el Paraíso, al igual que Calderón Tejada y Granada.

Durante estos procesos de urbanización, el área específica de lo que es ahora el lote correspondiente al Politécnico Grancolombiano quedó dentro de la Urbanización Bosque Calderón Tejada, la cual fue loteada y legalizada en el año de 1981. A principios de los años ochenta, en el predio "Bosque Calderón Tejada", propiedad de Grancolombiana de Vivienda Ltda. (Granvivienda), se tramitaron las licencias y permisos de construcción para las instalaciones de la universidad, los cuales fueron otorgados por Planeación Distrital bajo una estricta observación por parte de la CAR, debido a la condición de Reserva Forestal Protectora de la zona (CAR, 1981).

Desde ese entonces, ya se evidenciaba una degradación de los suelos por los procesos de erosión, hasta el punto que, en el permiso de construcción, se condiciona la tala de eucaliptos (árboles que constituían la mayor parte de la vegetación existente), por la presencia de suelo suelto y con agregados (CAR, 1981). Era tan grave la situación, que después de construirse la universidad, la Institución ordena un Inventario Forestal y de Paisajismo, con estudio de suelos.

Los resultados arrojados demuestran que en toda esta área se ha perdido la capa de ceniza volcánica, la cual aportaba los nutrientes suficientes a la vegetación anteriormente existente. Por otro lado, los análisis químicos demostraron que el suelo presente es pobre en nutrientes, posee una alta acidez y un alto contenido de aluminio, lo cual impide la asimilación de nutrientes por las plantas (Politécnico Grancolombiano Proyecto de Desarrollo Ltda,1981).

La conclusión de este trabajo dejó claro que no es adecuado mantener rodales de eucaliptos y se proponen soluciones como entresacas, la sustitución progresiva de este tipo de árboles por especies invasoras nativas y arbustos, además del recubrimiento de toda la zona con tierra negra para favorecer el empradizamiento (Politécnico Grancolombiano - Proyecto de Desarrollo Ltda, 1981).

Este estudio marcó las pautas a seguir. Sin embargo, la tala y sustitución de árboles está sujeta a la condición de Reserva Forestal Protectora, lo que impidió un mejor manejo del bosque y su entorno por parte de la Institución. A principios del 2001 con los permisos de tala otorgados por el D.A.M.A. para árboles enfermos o que podrían ser causantes de accidentes, se hizo una sustitución por especies nativas (Acto Administrativo, 2001). Sin embargo, esto estaba lejos de solucionar el grave problema de accidentalidad, degradación de suelos y pérdida de biodiversidad, por lo que se propuso este proyecto piloto del Politécnico Grancolombiano en unión con la CAR para realizar un estudio serio con acciones contundentes que lleven a mostrar las enormes posibilidades de restauración ecológica de los Cerros Orientales de Bogotá.

\section{Plan Piloto de la restauración ecológica del Campus}

Las plantaciones forestales de especies exóticas como eucaliptos, que se establecieron en años anteriores en los Cerros Orientales, han generando polémica al interior de las entidades ambientales por sus efectos sobre los suelos, el agua, la vegetación y la fauna local, sin desconocer su importancia y sus atributos en producción de madera y rentabilidad (Buttoud, 2003). 
Por esta razón, el Gobierno Nacional ha expedido normatividad que reglamenta y restringe el uso y las prácticas agrícolas y forestales en los Cerros Orientales. Sin embargo, esta legislación limita el adecuado manejo silvicultural de las plantaciones forestales exóticas establecidas previamente como se anota en el marco de referencia.

Cumpliendo con los lineamientos ambientales distritales y los requerimientos planteados por la CAR, a través de la autorización 026 (CAR, 2010) se diseñó el plan de restauración ecológica en el predio del Campus del Politécnico Grancolombiano, en la localidad de Chapinero, como mecanismo que permita introducir la cobertura vegetal nativa, acorde con la vocación de los Cerros Orientales y sus beneficios asociados.

La recuperación de la cobertura vegetal nativa es una actividad indispensable en el proceso de reconformación física y ecológica de terrenos. Entre otros, cumple con funciones como: apoyo y retención de la delgada capa de suelos que cubre el total del área afectada por el aprovechamiento forestal, proporciona condiciones adecuadas para la formación de suelos (nutrientes, humedad, cobertura), brinda condiciones adecuadas para la llegada y establecimiento de sucesiones vegetales propias.

El proyecto desarrollado en el Campus del Politécnico Grancolombiano, se basó en la caracterización física, la caracterización de los eucaliptos, el diagnóstico edafológico y el inventario forestal que correspondió a la primera parte del estudio. Con esto, se estableció el verdadero estado de afectación del terreno al nivel de suelos y flora, y la guía para seleccionar las actividades necesarias que se sucedieron a continuación.

El estudio pretendió cubrir los requisitos necesarios para el suministro de insumos, mano de obra, cronograma, equipos y mantenimiento de la recuperación de la capa de suelos, y la plantación de individuos de especies nativas de la parte de obra relacionada con la restauración (D.A.M.A. - Bachaqueros, 2002)

Para darle continuidad al proyecto y con anuencia de la CAR, se pidió la valoración de 200 árboles de Eucalipto adicionales a los ya mencionados anteriormente para tala con visita realizada por la CAR (Radicacion CAR, 2010).

\section{Objetivo General}

Diseñar y ejecutar un plan de mejoramiento ambiental en el Campus del Politécnico Grancolombiano que incluya un manejo forestal siguiendo el principio de precaución de acuerdo con la autorización No. 026 del 4 de agosto del 2010 dada por la CAR y efectuar procesos de conservación medioambiental en busca de restablecer el equilibrio natural y avanzar hacia una restauración ecológica del predio.

\section{Objetivos especíiticos}

1. Caracterizar los aspectos físicos y bióticos en el área de influencia del proyecto.

2. Realizar un inventario forestal para determinar la localización de los árboles de alto riesgo de volcamiento.

3. Diseñar y ejecutar el plan de manejo y aprovechamiento forestal.

4. Diseñar y ejecutar el plan de restauración ecológica para las áreas intervenidas del Campus, con base en la guía técnica de restauración para sitios con plantaciones de especies exóticas (Eucaliptos) (D.A.M.A.; O Manrique, 2004).

5. Diseñar el plan de manejo y monitoreo de la restauración ecológica. 


\section{Metodología}

El plan de tala y siembre fue ejecutado por la empresa Ingenieros Forestales Asociados Foresta Ltda (Durán, 2010)

\section{Primera etapa}

\section{Características de los aspectos físicos y bióticos}

Para el plan de manejo y monitoreo de restauración ecológicase diseñó un programa de mantenimiento en donde se identifican $y$ describen las actividades, plazosy presupuesto necesarios paramantener y establecer adecuadamente la vegetación arbóreay arbustiva plantada.

Se realizó un reconocimiento del Campus del Politécnico Grancolombiano y se establecieron las características físico bióticas del área teniendo en cuenta ubicación por coordenadas, hidrografía, altitud, clima y superficie.

\section{Inventario Forestal (Suárez-Calderón, 2000)}

Las zonas con presencia de eucaliptos se muestrearon siguiendo la metodología de inventario forestal diseñada por el Jardín Botánico de Bogotá, José Celestino Mutis. ${ }^{2}$ Su objetivo es la ubicación, numeración, identificación, y descripción en terreno del $100 \%$ de los individuos arbóreos existentes en el área de estudio.

Las variables analizadas según metodología adaptada fueron: número de árboles por zona, altura total, altura comercial, diámetro a la altura del pecho (DAP) y estado fitosanitario de los mismos.

\section{Ubicación del área de inventario}

Se inició la numeración de los eucaliptos, a partir del primer árbol localizado en el extremo suroriental del predio demarcado en campo. En las coordenadas 1002577 Este, 1004916 Norte y se finalizó en el extremo norte del predio donde se cumplía con la numeración autorizada para los 420 árboles.

\section{Medición y numeración}

Se identificaron los árboles presentes en las franjas de estudio, con su correspondiente nombre común y científico, midiendo el DAP con cinta métrica, con base en los lineamientos de medición señalados en el Artículo 10 del Decreto 1791 de 1996.

Posteriormente, cada árbol identificado y medido fue numerado consecutivamente a partir del número 1 hasta el 420. La marcación se realizó directamente sobre la corteza del árbol, raspándose una parte de ella y realizándola con pintura de esmalte, permitiendo su fácil identificación y ubicación en campo.

\section{Registro y procesamiento de la información}

El registro de las variables y observaciones recolectadas en campo se plasmaron en el formulario de campo, diseñado acorde con los objetivos del estudio para fustales.

Obtenida la información en campo se calculó el área basal y el volumen de cada una de las especies para lo cual se utilizó la hoja de cálculo de Microsoft Excel, procesando automáticamente los cálculos de acuerdo con las fórmulas convencionales usadas para la silvicultura de bosques plantados, información de importancia para la planificación de la empresa contratista (LemaTapias, 1995).

\section{Diseño v ejecución del plan de manejo v aprovechamiento forestal}

La tala se inició en octubre del 2010 y su finalización está programada para mayo del 2011. En el diseño del plan de aprovechamiento forestal se tuvieron en cuenta los siguientes parámetros:

a. Técnicos - referente a lo establecido para monocultivos de la especie Eucalyptus globulus y la ausencia total de prácticas de manejo silvicultural.

b. Sociales - referentes al derecho fundamental a la vida, que se ha de respetar a

2. Jardín Botánico de Bogotá, José Celestino Mutis 
la comunidad de la Institución, peatones y vecinos de los barrios circundantes que transitan por los alrededores del predio dado que los árboles perimetrales tienen inclinación hacia las viviendas, zonas de parqueo y de paso peatonal, arqueamiento del fuste y un alto riesgo de volcamiento.

c. Ambientales - referentes a la sustitución del monocultivo de árboles de Eucalipto por especies nativas con el fin de conformar varios estratos de vegetación, que a largo plazo estén constituidos por árboles $\mathrm{y}$ arbustos que cumplan las funciones de regulación del flujo de escurrimiento de aguas lluvias, mejoren la estabilidad de los taludes, disminuyan la acidificación y calidad del suelo, reduzcan el riesgo a los vecinos del sector, entre otras.

En virtud de lo anterior, tales son las razones por las cuales se hace necesario sustituir el monocultivo de árboles de Eucalipto.

\section{Manejo silvicultural}

El área de aprovechamiento es de $10 \mathrm{Has}$ dentro de las cuales las distancias de arrastre y transporte son relativamente cortas, por esta razón se implementó un sistema combinado de aprovechamiento, consistente en la instalación de campamentos de aserrío estacionarios, en los cuales dada las condiciones de la zona del proyecto, se transformara la madera con el uso de motosierra.

En el apeo de los árboles en las franjas del proyecto, se realizará la tala rasa de árboles, con el fin de:

- garantizar la sustracción de los árboles que presentan un mayor riesgo sobre la comunidad.

- favorecer la transición ecológica y ambiental de las zonas a restaurar.

- evitar el rebrote y la apropiación de terrenos nuevamente por la especie Eucalipto en las zonas aprovechadas.

En los campamentos establecidos se encuadraron las trozas, quitando los ori- llos y produciendo bloques de diferentes dimensiones de acuerdo a las posibilidades que generan los árboles apeados. Los fustes de los arboles ya desramados en el sitio de apeo, fueron arrastrados hasta el campamento principal donde se realizó la transformación primaria. Para el arrastre y transporte de los troncos se utilizarán los caminos internos del predio y los externos para la comercialización de los productos.

\section{Manejo de residuos}

Los orillos, leña, aserrín y demás sobrantes de la actividad forestal, fueron retirados de manera periódica y transportados a botaderos de residuos autorizados por las autoridades ambientales y/o pueden ser comercializados.

\section{Mano de obra}

Se conformaron dos (2) cuadrillas forestales, las cuales constan de:

- cinco (5) operarios capacitados y con experiencia, de los cuales dos (2) son aserradores, encargados de generar la transformación primaria de la madera en bloques

- un (1) maromero, que desarrolla las actividades de tala direccionada, ya sea por caída libre y/o por descope

- dos (2) auxiliares encargados del apoyo logístico, así como del desrame, troceo, clasificación y recolección de residuos

- un ingeniero forestal encargado de supervisar la ejecución de las actividades de la cuadrilla, inspeccionar la calidad y desarrollo del trabajo, hacer cumplir al personal las normas de seguridad industrial así como estar a cargo de todas las fases del proyecto.

\section{Prevención de incendios forestales}

Teniendo en cuenta que la zona de estudio ha sido sector de influencia en conatos de incendios forestales, durante el desarrollo del aprovechamiento forestal se tomaron las 
siguientes medidas para evitar la conflagración:

- se delimitaron los sitios apropiados de acopio de combustibles

- se dio parte al cuerpo de bomberos de Chapinero sobre las actividades silviculturales a desarrollar al interior del predio, pendientes de cualquier llamado de emergencia sobre el inicio de cualquier conato de incendio forestal en el lote y/o lotes aledaños

Materiales y equinos

Para el desarrollo de las actividades se contó con el siguiente equipamiento:

- 8 motosierras Sthill 650 para el apeo y aserrío

- 2 motosierras sthil 250 para el descope y manejo aéreo

- cable Tirfor de 6 toneladas

- 2 malacates de 2 y 4 toneladas respectivamente, para el direccionamiento del apeo

- manilas, poleas y guayas de diferentes longitudes y grosores para el arrastre y direccionamiento de los fustes.

Los operarios se dotaron con los elementos de seguridad industrial y protección personal requeridos para este tipo de labores (botas con puntera acerada, cascos, monogafas, overoles de fácil identificación en campo, guantes, tapa oídos, arneses de 4 puntos para trabajo en alturas). Otras herramientas secundarias utilizadas fueron machetes, lonas, picas, palancas, cuñas, $y$ demás que se requirieron.

\section{Plan de Corta}

Se calculó el aprovechamiento de 30 árboles/ semana por un periodo de 4 meses proyectados para le ejecución de las obras, hasta completar los 420 árboles otorgados dentro de la licencia concedida por la CAR.

\section{SEGUNDA ETAPA}

Diseño y ejecución del plan de restauración ecológica para las áreas intervenidas (MMAAcofore-Oimt, 2000)
La restauración ecológica se define como el proceso de alteración intencional de un hábitat para establecer un ecosistema definido, natural e histórico local. El objetivo de este proceso es imitar la estructura, la función, la diversidad y la dinámica del ecosistema original según la Society of Ecological Restoration (Jackson, Lopoukhine, \& Hillyard, 1995)

La plantación de una cobertura vegetal con especies nativas implica la ejecución de actividades relacionadas con la preparación del terreno, la selección de especies adecuadas, la plantación o trasplante de las mismas y el mantenimiento y seguimiento de la plantación, de forma que se garantice el establecimiento de las comunidades herbáceas.

Una vez finalizadas las actividades de aprovechamiento forestal al interior del predio, se inició la puesta en marcha de las prácticas silviculturales encaminadas a la recuperación y restauración ecológica, con base en los lineamientos generales, adoptados en la guía técnica para la restauración ecológica en áreas con plantaciones forestales (Dama; O Manrique, 2004).

Para el diseño del plan de restauración ecológica se tuvieron en cuenta los siguientes parámetros:

- la recuperación de la capa de suelos orgánicos útil para establecimiento de la vegetación herbácea

- la provisión de las condiciones edáficas adecuadas a los suelos para la arborización (vegetación arbórea y arbustiva) de los diseños florísticos planteados

- la inducción de procesos de formación y maduración de suelos necesarios para la recuperación integral

- el establecimiento y la descripción de las actividades o metodologías a seguir para llevar a cabo el proceso de recuperación de la vegetación nativa

- la identificación de las áreas objeto del tratamiento para recuperación de la vege- 
tación arbustiva y arbórea nativa

- la definición de los arreglos florísticos acorde con los requerimientos ecológicos y ambientales de las franjas de emergencia en el área de estudio, siguiendo los lineamientos del Protocolo Distrital de Restauración Ecológica

- la propuesta de las especies nativas para la sucesión vegetal.

Tipos de arborización (Provecto-Contraloría de Bogotá, 2000)

Para la restauración de la vegetación se contemplaron dos grandes zonas: Zona con Vegetación Protectora, inundable o no, según el caso y Zona con Vegetación de Ronda (inundable o no). Las oposiciones entre estas zonas están dadas por la plantación de algunas especies diferentes entre estas y la densidad de siembra. La vegetación protectora está orientada hacia la conservación y preservación de la fauna y atracción de la misma, y además tiene como función la protección de sectores de importancia ecológica en donde el tránsito humano es restringido o impedido en algunos casos, como prestar el servicio de ser sitio apropiado para anidación de aves y fauna en general.

\section{Restablecimiento de la cobertura vegetal}

Una vez finalizadas las labores de extracción y aprovechamiento de las franjas de emergencia expuestas en el plan de manejo se procedió a dar curso a los proceso de preparación y adecuación del terreno; se definieron los patrones sucesionales a implementar en el área de restauración con cobertura total de terreno de las nuevas especies nativas.

Debido a que el terreno no presentó situación homogénea en su estado sucesional, se utilizaron tres formas de siembra Arboretum y tres bolillos, de acuerdo a la conformación de cada zona. Se ajustó al Patrón de Plantación en
Parches Hexagonales o plantación reticular, compuesto por 7 árboles de especies nativas, distribuidos aleatoriamente en forma de hexágono, para que favorezcan la sucesión vegetal y la restauración de las condiciones ecológicas iniciales, utilizando una mezcla aproximada de 60 especies pertenecientes a 43 familias diferentes, que puedan integrarse y fortalecer la cobertura actual. Allí las especies pioneras o colonizadoras van encontrando condiciones igualmente propicias para continuar su proceso expansivo (Fundación Bachaqueros -D.A.M.A., 1999)

Para el restablecimiento de la cobertura vegetal se utilizaron especies vegetales de la flora nativa local y se siguió el patrón general de la sucesión secundaria, estableciendo en primera instancia, especies heliófilas colonizadoras formadoras de suelo, creadoras de condiciones de sombra (precursores leñosos) y en segundo lugar, especies arbóreas propias de la sucesión secundaria avanzada.

Se incluyeron también especies de crecimiento rápido y en lo posible abundante producción de hojarasca, para que al descomponerse contribuya al mejoramiento de las condiciones fisicoquímicas del suelo y en general a la estructuración de un micro hábitat más favorable para especies con menor tolerancia ecológica.

El restablecimiento de la cobertura vegetal se organizó de acuerdo con conceptos de diseño ecológico y arquitectónico. Se tomó en cuenta no sólo los criterios ecológicos y de establecimiento de hábitats, sino también criterios de uniformidad y transparencia, ubicación de cuerpos de agua, senderos peatonales y miradores.

Para el diseño del restablecimiento de la vegetación, se tuvo en cuenta el planteamiento 
con Zonas de Vegetación Protectora, Zonas de Vegetación de Ronda, Zonas de Vegetación Transicional, establecimiento de parches para Bosque melífero y Cercas Vivas. Estas zonas se definieron de acuerdo con las condiciones topográficas, estructurales y ecológicas.

\section{Manejo y monitoreo}

Para el plan de manejo y monitoreo de restauración ecológica se diseñó un programa de mantenimiento en donde se identifican y describen las actividades, plazos y presupuesto necesarios para mantener y establecer adecuadamente la vegetación arbórea y arbustiva plantada.

Esto se representó en una tabla resumen de las estrategias y recomendaciones técnicas para el correcto seguimiento y respectivo cuidado de la vegetación plantada en los diferentes sectores del predio.

\section{RESULTADOS}

A continuación se realiza una descripción y análisis de los resultados obtenidos en el inventario forestal y en la tala realizada posteriormente en el campus Institucional
El predio establecido con un monocultivo de la especie Eucalyptus globulus, en los años 70s representa un diseño de plantación forestal, el cual por la normatividad ambiental que rige los cerros orientales, presenta una ausencia total de prácticas de manejo silvicultural (Podas, entresacas, entre otras).

Esto ha dado como resultado individuos de porte arbóreo con unas condiciones fitosanitarias variables, de fustes alargados y ramificados de porte alto, con volúmenes bajos, de distancias de siembra hasta de 2 metros entre unidad por la presencia de rebrotes y con una tendencia alta a muy alta al volcamiento en las áreas con pendientes pronunciadas (decreto 1791 de 1996 y el acuerdo 28 de 2004 emanado de la CAR, dispone el aprovechamiento de árboles aislados, cuando se encuentren caídos o muertos por causas naturales, o para el control de emergencias fitosanitarias y la prevención de riesgos)

Distribución de la vegetación por altura

La distribución de la vegetación por clases de altura se realizó respecto al total de individuos registrados en el inventario dentro de la misma especie y se registra en la Tabla 1.

Tabla 1.Clasificación de la vegetación por Clases de Altura

\begin{tabular}{|l|l|l|l|l|l|l|l|l|l|}
\hline \multicolumn{2}{|l|}{ GRUPO I } & \multicolumn{2}{l|l|l|}{ GRUPO II } & \multicolumn{2}{l|}{ GRUPO III } & \multicolumn{2}{l|}{ GRUPO IV } & \multicolumn{2}{l|}{ GRUPO V } \\
\hline$<5 \mathrm{~m}$ & $5.01-10 \mathrm{~m}$ & \multicolumn{2}{l|l}{$10,1-20 \mathrm{~m}$} & $20,1-30 \mathrm{~m}$ & \multicolumn{2}{l|}{$>30.01 \mathrm{~m}$} \\
\hline cantidad & $\%$ & cantidad & $\%$ & cantidad & $\%$ & cantidad & $\%$ & cantidad & $\%$ \\
\hline 1 & 0.23 & 10 & 2.38 & 89 & 21.19 & 124 & 29.52 & 200 & 47.61 \\
\hline
\end{tabular}

El 47.61\% de los árboles corresponde a 200 individuos relacionados en el Grupo V con alturas mayores a 30m, el $29.52 \%$ representado en 124 individuos. Se encuentran en el Grupo IV, y el $21.19 \%$ representado en clase de altura del Grupo III correspondiente a 89 individuos; solamente el 1\% corresponde a la clase I y a un registro de un árbol maduro partido a esta altura por la caída de otro individuo. Existe un 2.38\% de individuos correspondientes a la clase Grupo II con apenas de $10 \mathrm{~m}$ de altura total, que puede corresponder a una localización sobre el nivel general de los demás individuos, o al error mínimo de apreciación del inventariado de campo. 
Características de los Eucalyptus globulus en el área de monocultivo:

- el $84 \%$ de ellos, presenta una ramificación alta, con distancias de siembra de hasta $2 \mathrm{~m}$, aumentando así la competencia por luz, espacio y nutrientes. Dado que el Eucalipto es una especie heliófita se observa la repercusión en la forma de los fustes

- el $66 \%$ de las copas son de forma asimétrica y se encuentran en buen estado

- el $62.2 \%$ de los árboles presentan un ángulo de inclinación importante, superior a $25^{\circ}$

- el $53 \%$ de los fustes se encuentran en estado regular, el $6.34 \%$ en estado bueno y el $40.41 \%$ en mal estado, eso en cuanto a su morfología

- el $6 \%$ presentan bifurcaciones a lo largo del fuste y el $12.34 \%$ tiene bifurcaciones basales correspondientes a rebrotes de tocones, de las ultimas talas realizadas hace algunos años

- el 39.09\% de los árboles inventariados, presentan fustes rectos, delgados y sanos, con bajos volúmenes de madera, pese a la edad de la plantación

- el diámetro a la altura del pecho (DAP) se encuentra en promedio de $0.23 \mathrm{~m}$.

- el $2.44 \%$ de árboles mostraron presencia de insectos, porcentaje muy bajo para considerar un brote de plaga; el 4.20\% son árboles parcialmente secos y el $0.91 \%$ secos en los cuales hay insectos barrenadores localizados en las zonas propensas a la pudrición

- la media de la Altura total (Ат) de los árboles se encuentra en $27.50 \mathrm{~m}$

- la altura comercial promedio es de $8.43 \mathrm{~m}$

- la población de porte arbóreo $61.43 \%$, presenta diferentes grados de daño mecánico generados por causas antrópicas (anillamiento, socavamientos en la corteza por intentos de corte fallidos) y tocones que evidencian el apeo antitécnico de árboles en la zona.

En términos generales, el estado fitosanitario de la plantación es muy regular al registrarse la presencia de hongos, cáncer, gomosis e insectos fitopatógenos.

El riesgo evaluado en la masa arbórea corresponde a un 38\% de los árboles con un nivel de riesgo ligero mientras el 61.72\% corresponde a árboles con ángulos de inclinación importantes.
El volumen bruto de madera en pie es de 744.93m3. de los cuales el volumen neto de madera comercial aprovechable es de aproximadamente $381 \mathrm{~m} 3$ (madera para aserrío).

\section{Restauración ecológica}

Se encontró que entre la vegetación predominante de la zona a restaurar se encuentran especies heliófitas con aptitud pionera y recuperación de suelos como lo son Myrcianthes leucoxyla, Alnus acuminata, Vallea stipularis, Duranta mutissi, Xylosma spiculiferum, Miconia reclinata, Solanum lycioides y Myrica parviflora; especies de fácil adaptación, control de erosión y buena regeneración natural como Baccharis bogotensis, Dodonea viscosa, Duranta mutisii y Myrica parviflora; en general se seleccionaron especies ornamentales con abundante floración, semillas y frutos que atraen principalmente avifauna. Se incluyen también especies inductoras de rastrojos y corredores ornamentales como Vallea stipularis, Xylosma spiculiferum, Miconia reclinata, Axinaea macrophylla y Cedrela montana, Clusia multiflora y Escallonia paniculata; así mismo especies importantes para la recuperación de suelos degradados y fijación de nitrógeno como Alnus acuminata, Smallanthus pyramidalis, Baccharis bogotensis, Dodonea viscosa, Duranta mutisii y Miconia reclinata; especies para la recuperación de suelos degradados y control de erosión como Xylosma spiculiferum, Myrica parviflora, Myrcianthes leucoxyla, Miconia reclinata, Duranta mutisii, Dodonea viscosa y Clusia multiflora (Bartholomäus, Rosa, Santos, Acero, \& Moosbrugger, 1998) (PerezArbelaez, 1978).

A continuación se describen los arreglos florales seleccionados de acuerdo con condiciones de estudio: 
Arreglo florístico No. 1 introducción de matorral

Caracteristicas:

El arreglo florístico de matorral, representa la transición entre los tipos fisionómicos estructurales. Además la cobertura de matorral permite el estado sucesional intermedio, que da una mejor protección al suelo desnudo y aporta altos índices de humedad al suelo.

\section{Composición Florística}

- Módulo 1A: Cucharo + Laurel de Cera + curapín + CEDRO

- Módulo 1B: Duraznillo + Campanilla + Hayuelo + CAUCHO SABANERO

- Módulo 1C: Garrocho + Feijoa + Ciro + ARRAYAN

\begin{tabular}{|l|l|l|l|l|l|l|}
\hline $\begin{array}{l}\text { Distancia de } \\
\text { plantación }\end{array}$ & $\begin{array}{l}\text { Área de } \\
\text { ocupación }\end{array}$ & $\begin{array}{l}\text { Sistema de } \\
\text { plantación }\end{array}$ & $\begin{array}{l}\text { Cantidad de } \\
\text { individuos } \\
\text { por parche }\end{array}$ & $\begin{array}{l}\text { Cantidad } \\
\text { de } \\
\text { Parches }\end{array}$ & $\begin{array}{l}\text { Numero de } \\
\text { conectores }\end{array}$ & $\begin{array}{l}\text { Cantidad de } \\
\text { individuos } \\
\text { por arreglo }\end{array}$ \\
\hline $\begin{array}{l}3 \mathrm{~m} \text { y } 5 \mathrm{~m} \text { de } \\
\text { acuerdo con el } \\
\text { porte del árbol, } \\
3 \text { transición } \\
\text { arbusto árbol, } \\
\begin{array}{l}\text { 5m entre } \\
\text { árboles. Entre } \\
\text { parches } 4 \mathrm{~m}\end{array}\end{array}$ & $64 \mathrm{~m} 2$ & $\begin{array}{l}\text { Parche hexa- } \\
\text { gonal, especies } \\
\text { Cedro, Caucho } \\
\text { sabanero, } \\
\text { Arrayán como } \\
\text { elemento prin- } \\
\text { cipal central del } \\
\text { parche. }\end{array}$ & 7 & 9 & $\begin{array}{l}\text { entre parches } \\
\text { 2 individuos } \\
\text { plantados } \\
\text { cada 3 a 5 } \\
\text { metros }\end{array}$ & $\begin{array}{l}36+20 \\
\text { conectores }\end{array}$ \\
\hline
\end{tabular}

Resultados esperados a mediano y largo plazo

En la plantación, el Cedro, Caucho y Arrayán tendrán la función de precursor leñoso, adecuando el terreno para el establecimiento del laurel de cera y los otros acompañantes del parche, el cual actuaría como especie dominante. Así mismo, esta especie en compañía del tuno, adecúan el suelo apor- tando grandes cantidades de materia orgánica manteniendo la humedad del suelo y activan el desarrollo de microorganismos. Adicionalmente, adecúan las condiciones del sitio para el establecimiento y sirven de alimento y percha para avifauna generando la dispersión de semillas y por lo tanto la propagación de estos agregados 


\section{Ejemplo de parche Tipo 1 Módulo IC}

Introducción de Matorral

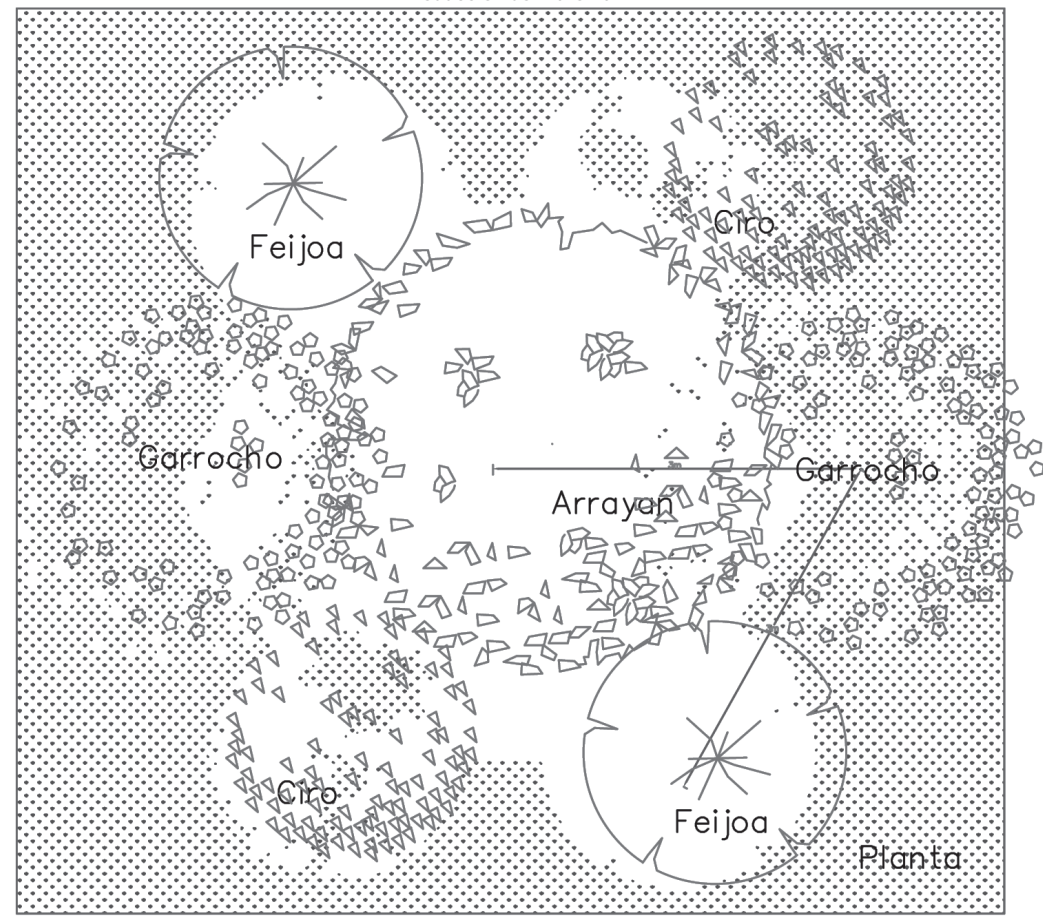

Planta

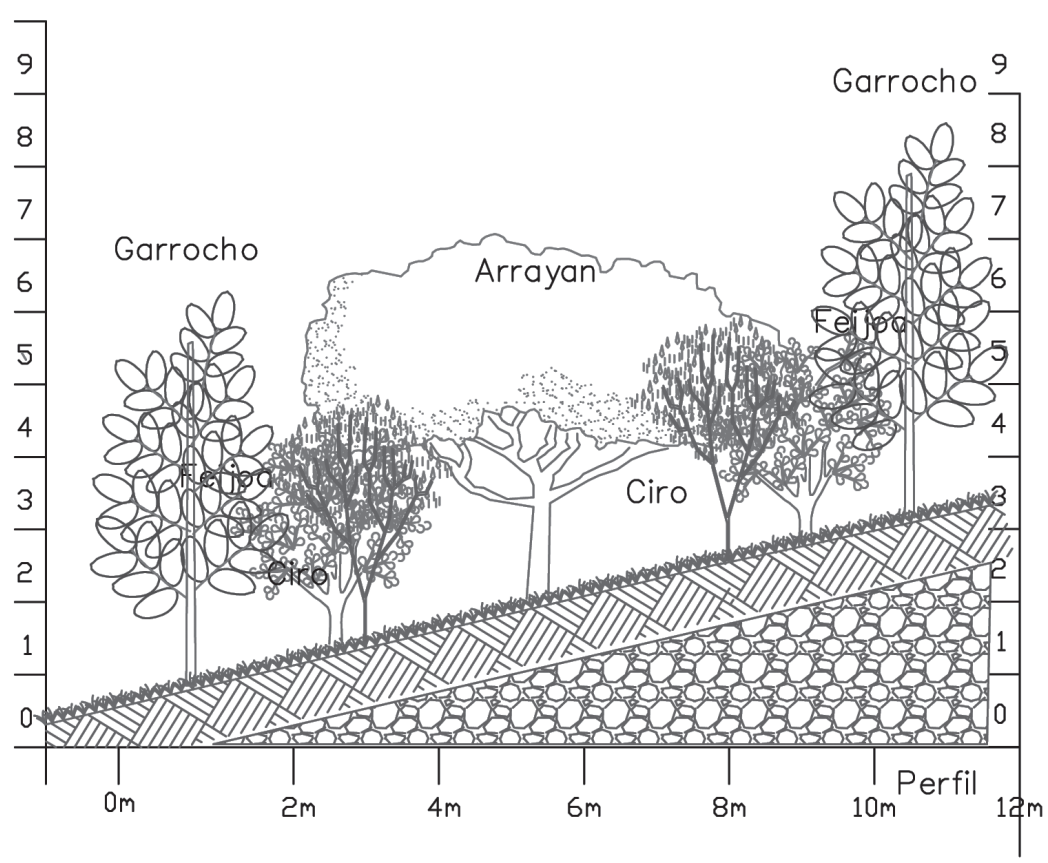


Arreglo floristico No. 2 establecimiento de bosque protector medio a alto

\section{Caracteristicas}

El arreglo florístico de bosque protector medio a alto representa la transición entre los tipos fisionómicos estructurales de arbustivos a arbóreos, presentando a la especie Acacia de hoja ancha, Mano de oso y Sangregado como elemento principal del parche, y creando un segundo estrato de arboles más bajos entre arbustivos, enredaderas y bejucos.

\section{Composición Floristica}

- Módulo 2A: Mangle de tierra fría, Jazmín del cabo, CORONO

- Módulo 2B: Curapín, Caballero de la noche, Raque, Mano de oso

- Módulo 2C: Arrayan mandarino, Tíbar, Sauco, SANGREGAO

- Módulo 2D: Sauco garrocho, Cajeto, Chicala, MANO DE OSO

\begin{tabular}{|l|l|l|l|l|l|l|}
\hline $\begin{array}{l}\text { Distancia de } \\
\text { plantación }\end{array}$ & $\begin{array}{l}\text { Área de } \\
\text { ocupación }\end{array}$ & $\begin{array}{l}\text { Sistema de plan- } \\
\text { tación }\end{array}$ & $\begin{array}{l}\text { Cantidad de } \\
\text { individuos } \\
\text { por parche }\end{array}$ & $\begin{array}{l}\text { Cantidad } \\
\text { de } \\
\text { Parches }\end{array}$ & $\begin{array}{l}\text { Número de } \\
\text { conectores }\end{array}$ & $\begin{array}{l}\text { Cantidad de } \\
\text { individuos } \\
\text { por arreglo }\end{array}$ \\
\hline $\begin{array}{l}\text { 4m de acuerdo } \\
\text { al porte del } \\
\text { árbol, 3m entre } \\
\text { parches }\end{array}$ & $75 \mathrm{~m}^{2}$ & $\begin{array}{l}\text { Parche hexagonal, } \\
\text { especies Acacia } \\
\text { hojiancha, Mano de } \\
\text { oso, Sangregado } \\
\text { Hojiancho como } \\
\text { elemento principal } \\
\text { central del parche. }\end{array}$ & 7 & 14 & $\begin{array}{l}\text { entre } \\
\text { parches 2 } \\
\text { individuos } \\
\text { plantados } \\
\text { cada } \\
\text { 4metros }\end{array}$ & $\begin{array}{l}98+36 \\
\text { conectores }\end{array}$ \\
\hline
\end{tabular}

\section{Resultados esperados a mediano y largo plazo}

En la plantación, el Curapín, el Mangle y el Arrayán tienen la función de precursores leñosos, adecuando el terreno para el establecimiento del Sangregado y el Mano de Oso como eje principal del parche, el cual actuaría como especie dominante. Así mismo, adecúan el suelo aportando grandes cantidades de materia orgánica manteniendo la humedad del suelo y activan el desarrollo de microorganismos; Adicionalmente, sirven de alimento y percha para avifauna generando la dispersión de semillas y por lo tanto propagación de estos agregados. 


\section{Ejemplo de parche tipo 2 Módulo 2B}

Establecimiento de Bosque Protector Medio a Alto

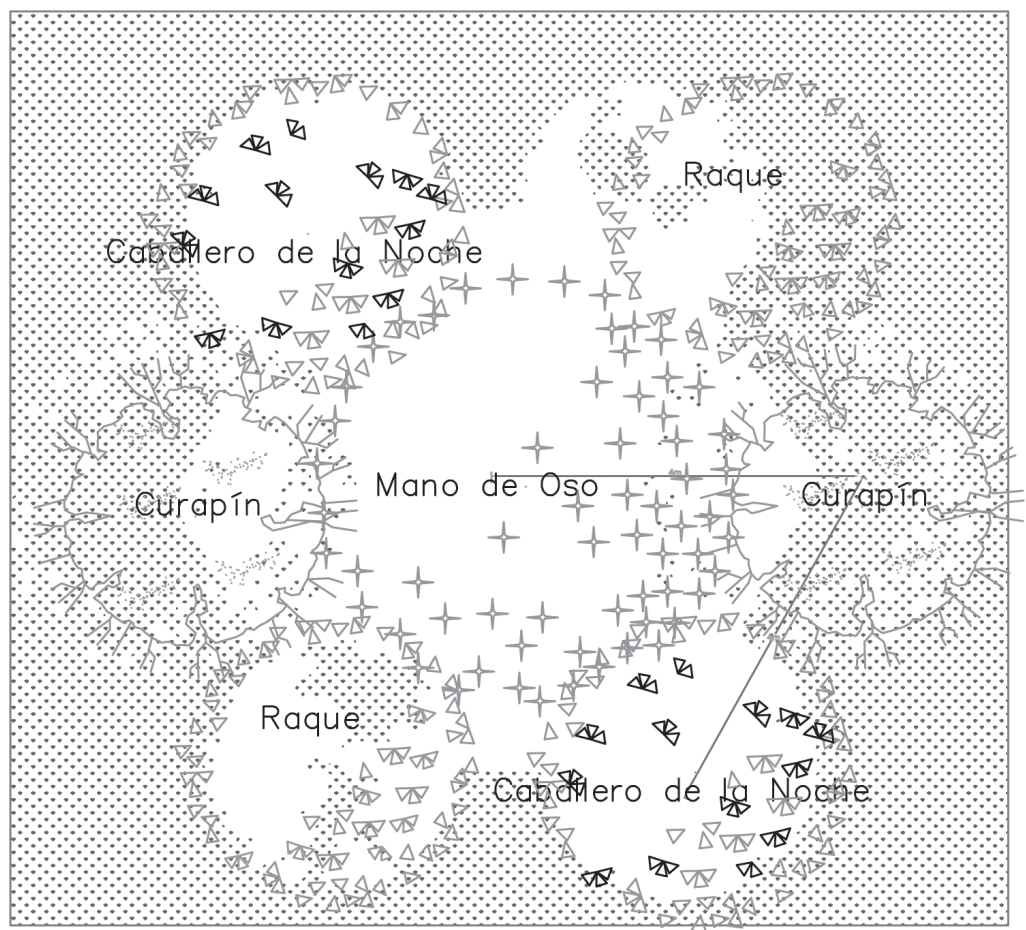

Planta

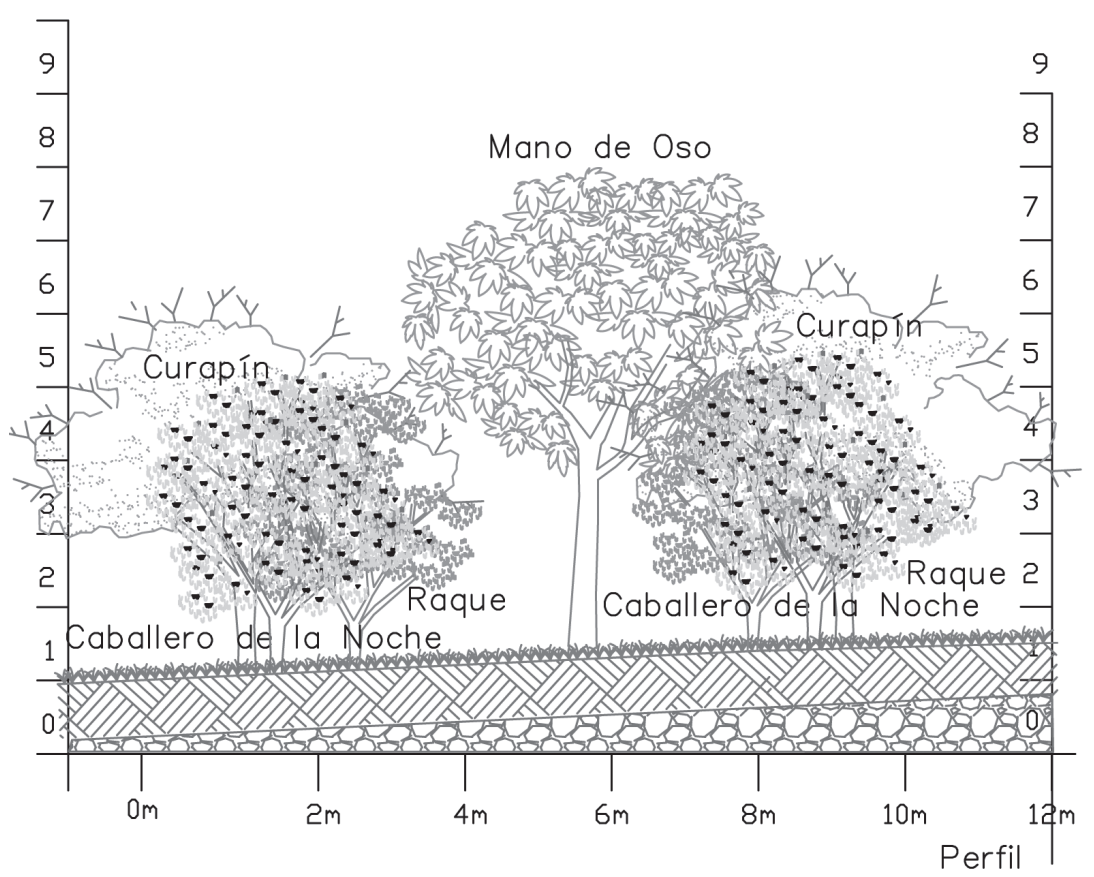


Arreglo florístico No. 3 establecimiento de bosque protector con precursores leñosos

Caracteristicas

La incorporación de precursores leñosos representa la entrada de especies arbóreas de alto porte con diseños de copas amplias y abundante follaje, que generan diversidad. Tipos fisionómicos estructurales de arbustivos a arbóreos que acompañan el arreglo, presentan a la especie Roble, Nogal y Cedro, como elemento principal del parche

\section{Composición Florística}

- Módulo 3A: Carbonero rojo, Cerezo, Níspero, NOGAL

- Módulo 3B: Sietecueros, Aliso, Gurrubo, CEDRO

- Módulo 3C: Curapín, Cajeto, Siete Cueros, ROBLE

\begin{tabular}{|l|l|l|l|l|l|l|}
\hline $\begin{array}{l}\text { Distancia de } \\
\text { plantación }\end{array}$ & $\begin{array}{l}\text { Área de } \\
\text { ocupación }\end{array}$ & $\begin{array}{l}\text { Sistema de } \\
\text { plantación }\end{array}$ & $\begin{array}{l}\text { Cantidad de } \\
\text { individuos } \\
\text { por parche }\end{array}$ & $\begin{array}{l}\text { Cantidad } \\
\text { de Parches }\end{array}$ & $\begin{array}{l}\text { Número de } \\
\text { conectores }\end{array}$ & $\begin{array}{l}\text { Cantidad de } \\
\text { individuos } \\
\text { por arreglo }\end{array}$ \\
\hline $\begin{array}{l}5 \mathrm{~m} \text { de acuerdo } \\
\text { al porte del } \\
\text { árbol, } 3 \mathrm{~m} \\
\text { transición } \\
\text { arbusto } \\
\text { árbol, } 5 \mathrm{~m} \\
\text { entre arboles } \\
\text { Distancia entre } \\
\text { parches } 5 \mathrm{~m}\end{array}$ & $80 \mathrm{~m}^{2}$ & $\begin{array}{l}\text { Parche } \\
\text { hexagonal, } \\
\text { especie Roble, } \\
\text { Nogal, Cedro } \\
\text { como elemento } \\
\text { principal } \\
\text { central del } \\
\text { parche. }\end{array}$ & 7 & 7 & $\begin{array}{l}\text { } \\
\text { entre parches } \\
\text { plantados } \\
\text { cada } 5 \text { metros }\end{array}$ & $\begin{array}{l}49+20 \\
\text { conectores }\end{array}$ \\
\hline
\end{tabular}

\section{Resultados esperados a mediano y largo plazo}

En la plantación, el Carbonero y el Aliso tienen la función de precursores leñosos, adecuando el terreno para el establecimiento del Roble, Nogal y Cedro cómo elemento principal del parche, el cual actuaría como especie dominante. Así mismo, el Cajeto sirve como barrera aislante del parche; las especies acompañantes aportarán grandes cantidades de materia orgánica; adicionalmente, sirven de alimento y percha para avifauna generando la dispersión de semillas y por lo tanto propagación de estos agregados. 


\section{Ejemplo de parche tipo 3 Módulo $3 \mathrm{C}$}

Establecimiento de Bosque Protector con precursores leñosos.

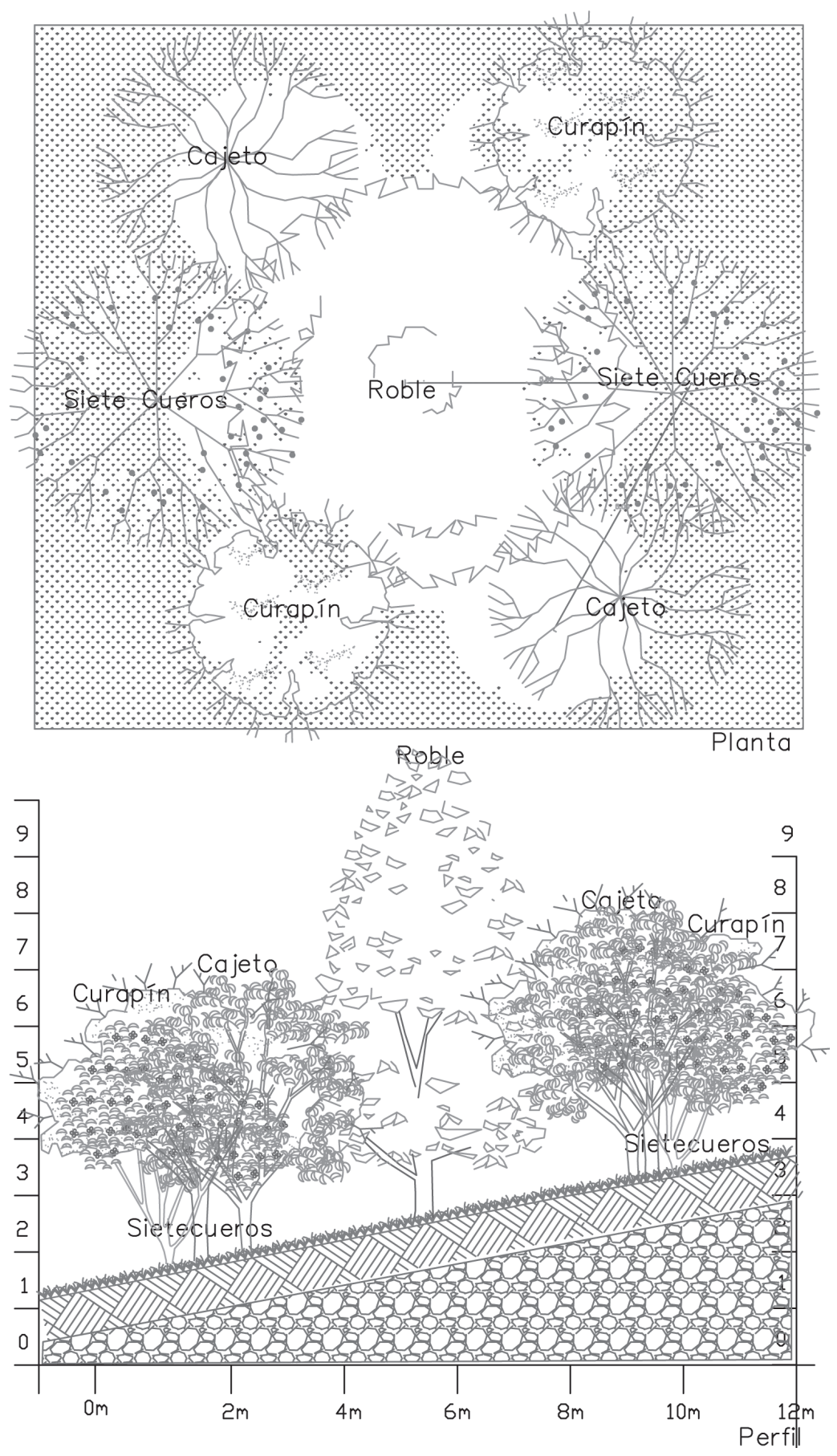




\section{PRECURSORES LEÑOSOS COMO CONECTORES DE PARCHES DEVEGETACIÓN}

\section{Características}

Los conectores entre parches de vegetación, son de vital importancia porque están encargados de generar corredores transicionales entre parches de vegetación, garantizando la homogeneidad en la dispersión y composición florística a implementar, además de cumplir distintas funciones como precursores leñosos, sirven como dispersores y perchas para avifauna.

\section{Composición Florística}

Tíbar, Garrocho, Mano de Oso, Aliso, Sauco, Chilco, Arrayan, Corono, Laurel de Cera, Laurel Hojipequeño, Ciro, Arupo, Siete Cueros, Roble, Caballero de la Noche, Raque, Duraznillo, Aliso, Cedro, Roble, Falso pimiento, Sauco, Garrocho, Feijoa, Nogal, Laurel de Cocina, Arrayan, Arrayan Mandarino

\begin{tabular}{|c|c|c|c|c|c|}
\hline $\begin{array}{l}\text { Distancia de } \\
\text { plantación }\end{array}$ & $\begin{array}{l}\text { Área de } \\
\text { ocupación }\end{array}$ & $\begin{array}{l}\text { Sistema de } \\
\text { plantación }\end{array}$ & $\begin{array}{l}\text { Cantidad de } \\
\text { individuos } \\
\text { por conector }\end{array}$ & $\begin{array}{l}\text { Número de } \\
\text { conectores }\end{array}$ & $\begin{array}{l}\text { Cantidad de } \\
\text { individuos: }\end{array}$ \\
\hline $\begin{array}{l}3 m \text { y } 5 m \text { de acuerdo } \\
\text { con el porte del árbol, } \\
3 m \text { transición arbusto } \\
\text { árbol, } 5 \mathrm{~m} \text { entre } \\
\text { árboles. }\end{array}$ & $10 m^{2}$ & $\begin{array}{l}\text { Plantación en } \\
\text { bloque lineal }\end{array}$ & 1 & $\begin{array}{l}\text { entre parches } 1 \\
\text { individuos plan- } \\
\text { tados cada } 3 \text { a } 5 \\
\text { metros }\end{array}$ & 60 \\
\hline
\end{tabular}

\section{Resultados esperados a mediano y largo plazo}

Las distintas especies usadas para la transición entre parches funcionan como barrera aislante del parche. Las especies acompañantes aportarán grandes cantidades de materia orgánica manteniendo la humedad del suelo y activarán el desarrollo de microorganismos. Adicionalmente, sirven de alimento y percha para avifauna generando la dispersión de semillas y por lo tanto, propagación de estos agregados.

\section{MANTENIMIENTO DEVEGETACIÓN ARBÓREA Y ARBUSTIVA}

Una vez implementadas las actividades de restablecimiento de la vegetación dentro del predio en ambos costados, se prosiguió con la etapa de mantenimiento, durante la cual se adelantan las labores que aseguran el establecimiento y buen desarrollo de la vegetación arbórea y arbustiva plantada.
El mantenimiento se realizó en un año al cabo del cual se entrega un informe y se registran las actividades de mantenimiento y las buenas prácticas ambientales relacionadas a la CAR como parte de los reportes generados como proyecto piloto. Se espera poder continuar con el proyecto conjunto y así desmontar paulatinamente la plantación de Eucalipto, a cambio de la restauración ecológica de las zonas degradadas y enriquecimiento con especies nativas en zonas altas del predio. Esto se mostraría como un caso exitoso de restauración de los Cerros Orientales de Bogotá que incluiría las variables de tiempo, requerimientos y manejo de los procesos.

La tabla que se presentará a continuación, resume las estrategias y recomendaciones técnicas a plantear para el correcto seguimiento y respectivo mantenimiento a la vegetación plantada en los diferentes sectores del predio y que fueron objeto de restauración ecológica 


\section{Tabla № 5 Resumen del plan de Seguimiento y Mantenimiento de Vegetación}

\section{Descripción, Metodología y Momento de ejecución de Mantenimiento de árboles plantados}

\begin{tabular}{|c|c|}
\hline Actividadl: & $\begin{array}{l}\text { Replanteo } \\
\text { Se realizará esta actividad sólo a los árboles que no presenten coberturas vegetales rastreras y/0 } \\
\text { herbáceas existentes en los humedales debido a que son importantes en los procesos de sucesión } \\
\text { ecológica. }\end{array}$ \\
\hline Actividad2: & $\begin{array}{l}\text { Fertilización } \\
\text { Esta actividad se realizará en todos los árboles y arbustos plantados, los cuales se abonarán con (10) } \\
\text { gramos de triple quince. La primera fertilización se realizará a los } 45 \text { días después de la plantación y la } \\
\text { segunda al tercer mes después de la plantación, la tercera y última a los } 9 \text { meses. }\end{array}$ \\
\hline Actividad3: & $\begin{array}{l}\text { Riego } \\
\text { Para garantizar el adecuado desarrollo de los árboles, se suministrarán 10gr de Hidroretenedor radicular } \\
\text { y tres (3) litros de agua por cada árbol, durante la primera semana posterior a la plantación, posterior- } \\
\text { mente, cada quince días durante el primer mes y luego cada treinta (30) días teniendo en cuenta las } \\
\text { condiciones atmosféricas. Se realizarán cinco (5) riegos en total. }\end{array}$ \\
\hline Actividad4: & $\begin{array}{l}\text { Re tutorado A cada árbol o arbusto que lo requiera se le reinstalará el tutor. Este debe ser de madera } \\
\text { seca, recto, sin resaltes y con su extremo inferior apuntalado, con el fin de facilitar el hincado en el terreno } \\
\text { a setenta y cinco (50) centímetros de profundidad. El amarre se hará con cabuya de fique y de manera } \\
\text { que no se lastime el material vegetal. }\end{array}$ \\
\hline Actividad5: & $\begin{array}{l}\text { Replante } \\
\text { Se plantarán nuevamente los árboles que se mueran durante los primeros meses, al quinto mes posterior } \\
\text { a la siembra. Para estos efectos se considera una mortalidad del } 8 \% \text { del material vegetal plantado. }\end{array}$ \\
\hline Actividad6: & $\begin{array}{l}\text { Control de malezas } \\
\text { Es necesario hacer el control de vegetación que aparece espontáneamente dentro de las plantaciones, } \\
\text { especialmente el pasto "kikuyo", para eliminar la competencia con las especies plantadas incluso con } \\
\text { los arbustos y árboles. } \\
\text { El control debe iniciarse en forma inmediata a la plantación y prolongarse por lo menos durante la etapa } \\
\text { de mantenimiento (seis meses), de ser posible, en los planes de seguimiento, se debe seguir con el } \\
\text { control. } \\
\text { El control se debe hacer en forma cuidadosa, ya que dentro de la maleza aparecen especies de arbustos } \\
\text { o árboles deseables, pertenecientes a estadios más avanzados de la etapa sucesional. }\end{array}$ \\
\hline Actividad7: & $\begin{array}{l}\text { Enfermedades y plagas } \\
\text { Una de las mejores defensas de la plantas contra las plagas es su vitalidad, por lo tanto una de las } \\
\text { medidas de prevención más importantes, es la de garantizar el desarrollo vigoroso de las plantas esta- } \\
\text { blecidas. } \\
\text { Ante el ataque de ataques de insectos dañinos y enfermedades, se debe identificar el elemento dañino, } \\
\text { para aplicar el correctivo específico mediante fumigación directa a la plantación. } \\
\text { Es necesario observar la posible ocurrencia de ataque de roedores (especialmente ratas domésticas) } \\
\text { sobre alguna o algunas de las especies utilizadas y en caso tal, efectuar los controles correspondientes } \\
\text { preferiblemente mecánicos, para no afectar el desarrollo normal de la vegetación. }\end{array}$ \\
\hline
\end{tabular}




\begin{tabular}{|l|l|}
\hline Actividadd8: & $\begin{array}{l}\text { Entrega de Material Vegetal } \\
\text { Una vez finalizada la etapa de mantenimiento de las especies, al cabo de los } 12 \text { meses, se efectuará la } \\
\text { entrega oficial del término de las obras de restauración de la vegetación a la entidad administradora, la } \\
\text { cual asumirá el, seguimiento y monitoreo de manera integral. }\end{array}$ \\
\hline Lugar deapilicación. & Ver Plano 2 - DISEÑO DE RESTAURACIÓN ECOLÓGICA \\
\hline Cantidadles deobra & 420 árboles \\
\hline Equiposymaquunaria & Herramientas menores tipo Palas, Picas, Barras, Carretillas tipo Buggy \\
\hline
\end{tabular}

\section{COMUNICACIÓN DEL SISTEMA DE GESTIÓN AMBIENTAL A LA COMUNIDAD}

Los integrantes del comité ambiental consideraron que los cambios causados en el Campus por la tala de los árboles y la nueva disposición de los arreglos florísticos, podría generar en la comunidad reacciones de aceptación o derechazo. Por lo tanto se planeó toda una estrategia de comunicación y acercamiento a la comunidad antes, durante y posterior al proceso que da cuenta de los procesos, acciones y compromisos del Sistema de Gestión Ambiental de la Institución. El cuadro a continuación es un ejemplo de la programación que se actualiza mes a mes.

\begin{tabular}{|l|l|l|l|}
\hline & TEMA & MEDIO & FECHA \\
\hline Página Web & $\begin{array}{l}\text { Siembra de especies nuevas } \\
\text { en el Poli }\end{array}$ & $\begin{array}{l}\text { Artículo página } \\
\text { Web }\end{array}$ & Diciembre 152010 \\
\hline Campaña No. 1 & $\begin{array}{l}\text { ¿Sabías que hemos comenzado } \\
\text { el proceso de certificación } \\
\text { ambiental ISO 14001? } \\
\text { Paso 1: restauración del } \\
\text { campus con árboles nativos. } \\
\text { Recuperación y conservación } \\
\text { de los suelos y el agua. }\end{array}$ & $\begin{array}{l}\text { Video walls } \\
\text { Página Web } \\
\text { 3 Pasacalles } \\
\text { 1 Pendón }\end{array}$ & $\begin{array}{l}\text { Enero 22 } 2011 \\
\text { Enero 22 a febrero } 42011 \\
\text { Feb 22 a marzo } 182011 \\
\text { Feb 22 a marzo } 182011\end{array}$ \\
\hline Capacitación docentes & Información general SGA & $\begin{array}{l}\text { Reuniones de } \\
\text { docentes }\end{array}$ & Enero 24 a 312011 \\
\hline Inducción estudiantes nuevos & Información general SGA & Charla & Enero 22 \\
\hline Página Web & $\begin{array}{l}\text { El Poli contribuye al ecosistema } \\
\text { de la zona }\end{array}$ & $\begin{array}{l}\text { Articulo página } \\
\text { Web }\end{array}$ & $\begin{array}{l}\text { Enero 2011 } \\
\text { Febrero 2011 }\end{array}$ \\
\hline Página Web & $\begin{array}{l}\text { Información general SGA } \\
\text { Politécnico }\end{array}$ & $\begin{array}{l}\text { Link página Web } \\
\text { politécnico }\end{array}$ & Enero 2011 \\
\hline Página Web & $\begin{array}{l}\text { Puntos ecológicos para la clasi- } \\
\text { ficación de la basura }\end{array}$ & $\begin{array}{l}\text { Articulo página } \\
\text { Web }\end{array}$ & Febrero 1 de 2011 \\
\hline Emisora Poliradio programa \\
Poliplanet & $\begin{array}{l}\text { SGA, programas ambientales, } \\
\text { plan de tala y restauración } \\
\text { campus }\end{array}$ & Emisora & Febrero 152011 \\
\hline Página Web & $\begin{array}{l}\text { SGA inicia segunda etapa: } \\
\text { Invitación a participar progra- } \\
\text { mas residuos, agua y energía }\end{array}$ & $\begin{array}{l}\text { Video y artículo } \\
\text { página Web }\end{array}$ & Febrero 25 2011 \\
\hline
\end{tabular}


La comunicación sobre el plan de tala de eucaliptos y restauración del Campus se incluyó como uno de los puntos más importantes inserto en el SGA. Al inicio del semestre se llevaron a cabo 7 reuniones cuya función principal fue dar una primera información oficial a las facultades (283 asistentes), a los nuevos estudiantes y al resto de la comunidad que hace parte del Politécnico Grancolombiano (2.000 asistentes entre empleados, docentes y nuevos estudiantes)

Los temas tratados en su orden fueron:

1. Inicio de un proceso de certificación ambiental.

2. Proyecto de certificación: etapas, metodología, cronograma.

3. Política ambiental, objetivos y metas.

4. Programas ambientales: manejo de residuos, manejo del agua, eficiencia energética, empleo responsable de productos, cultura ambiental, manejo de los jardines del Campus y educación ambiental, son las actividades generales a desarrollar en cada uno.

5. Estrategias a implementar: de comunicación, de capacitación, de información.

6. Actividades desarrolladas a la fecha.

7. Plan de tala y restauración del campus: razones, metodología, beneficios.

También se realizaron capacitaciones a docentes, con el fin de buscar un canal de comunicación directo con los estudiantes, para transmitirles la primera información del SGA y despertar la curiosidad e interés en ellos a través de las clases.

Con estas acciones se logró un excelente clima de aprobación e involucramiento con propuestas concretas por parte de docentes, estudiantes y empleados en generar para apoyar y ayudar en la consolidación de los procesos explicados.

\section{Conclusiones}

Un ecosistema deteriorado como el que se presenta en el Politécnico Grancolombiano es incapaz de regenerarse por sí solo y es necesaria la intervención humana. Esto no significa que éste no sea productivo, en efecto, produce bienes y servicios para la sociedad, pero no puede recuperar las condiciones originales debido a la pérdida de alguno de sus atributos clave como suelos, biota, geomorfología, hidrología, entre otros.

Es importante aclarar que restaurar ecológicamente no es reforestar, sino estimular los procesos de regeneración natural, donde se presenta un efecto multiplicador. Estas acciones no se hacen exclusivamente con vegetación nativa, las plantas exóticas pueden servir como pioneras en el restablecimiento de una vegetación acorde, en zonas severamente degradadas. Sin embargo, en este estudio solamente se dispuso plantar especies nativas.

La restauración ecológica propuesta en el Campus no pretende el restablecimiento de los atributos estructurales y funcionales de los ecosistemas. En realidad, alcanzar estos objetivos es muy difícil, pues casi siempre las condiciones ecológicas se encuentran irreversiblemente alteradas y no es viable en un ecosistema esas condiciones. Por eso, lo que se propuso fue ir hacia la restauración ecológica del predio.

El restablecimiento de la cobertura vegetal se debe enfocar a la estructuración de vegetación arbórea propicia para recuperación de atributos de los ecosistemas nativos (alisos, tunos, entre otros).

Con base en las consideraciones mencionadas, las plantaciones tendrán como meta específica lograr el establecimiento de una cobertura vegetal con la mayor biomasa y diversidad posibles, hasta que alcancen un estado de desarrollo donde la comunidad artificialmente instaurada, sea capaz de auto sostenerse y de continuar autónomamente el proceso de sucesión.
Un ecosistema deteriorado como el que se presenta en el Politécnico Grancolombiano es incapaz de regenerarse por sí solo y es necesaria la intervención humana. Esto no significa que éste no sea productivo, en efecto, produce bienes y servicios para la sociedad, pero no puede recuperar las condiciones originales debido a la pérdida de alguno de sus atributos clave como suelos, biota, geomorfología, hidrología, entre otros. 
Es importante tener en cuenta también, la función estética del restablecimiento de la cobertura vegetal, el porte de la especie, cobertura, forma, textura de follaje y color de las hojas, flores y frutos. Las especies seleccionadas deben guardar armonía paisajística con las especies existentes y tolerar los niveles de contaminación atmosférica del lugar.

Así mismo, se debe trabajar con las funciones ecológicas propias de la vegetación como son amortiguar los altos grados de contaminación ambiental, servir de hábitat natural de especies faunísticas importantes, regular el clima, aportar estabilidad a suelos y regular los ciclos hídricos entre el agua subterránea y la superficial

Se espera que el ecosistema a medida que se vaya restaurando sea auto sostenible al mismo grado que su ecosistema de referencia y que tenga el potencial de persistir indefinidamente bajo las condiciones ambientales existentes. No obstante, los aspectos de su biodiversidad, estructura y funcionamiento podrían cambiar como parte del desarrollo normal del ecosistema y podrían fluctuar en respuesta a acontecimientos normales y periódicos aislados de estrés y de alteración de mayor trascendencia.

Una estrategia fundamental que se debe prever desde un comienzo, es la de incorporar, de la manera más dinámica y efectiva posible a la comunidad circundante, para que participe en todas las actividades de planificación, administración y manejo de los proyectos que se establezcan a través de procesos de participación y cogestión.

\section{Bibliografía}

1. Acto Administrativo. (28 de Febrero de 2001). Resolucion 320. Bogotá, Colombia: Departamento Técnico Administrativo del Medio Ambiente, D.A.M.A.

2. ACUERDO O28 DEL 2004. (s.f.). por el cual se regula el uso, manejo, aprovechamiento de los bosques y la flora silvestre y la movilizacion de sus productos en la jurisdiccion de la Corporacion Autonoma Regional de Cundinamarca CAr. Bogotà, Colombia, Diario Oficial 45769.

3. Alcaldía Local de Chapinero. (2001). Diagnóstico Local con Participacion Social: Localidada de Chapinero. Bogotá: Alcaldía Local de Chapinero.

4. Avendaño, H., Camacho, C., \& Castro, P. (2004). Resultado de la revisión ambiental inicial en la Institución Universitaria Politécnico Grancolombiano. Politécnico. 2004. 68 - 87.

5. Bartholomäus, A., Rosa, A. D., Santos, J., Acero, L., \& Moosbrugger, W. (1998). El Manto de la Tierra. Flora de los Andes. Bogotá, Colombia: CAR y GTZ.

6. Buttoud, G. (2003). Prioridad a la reforma y reorientación del humilde plan de manejo forestal. Actualidad Forestal, 11 (1), 31- 36.

7. Camacho, C. (2007). Memorias del IV Seminario Internacional Universidad Medio Ambiente. El Sistema de Gestion Ambiental del Politécnico Grancolombiano. Bogotá: UDCA Vol. II.

8. Camacho, C. (2005b) Propuesta de Implementación de un Sistema de Gestión Ambiental para Campus Universitario. Poliantea, 20 - 43.

9. Camacho, C., Quintero, J., \& Muñoz, A. (2004). Diagnóstico del Campus de la Institución Universitaria Politécnico Grancolombiano. Poliantea, 26 - 47. 
10. CAr. (1981). Informe Visita Ocular a las Instalaciones del Centro Educativo, Politécnico Grancolombiano. Bogotá, Corporación Autónoma Regional de Cundinamarca.

11. Car. (4 de Agosto de 2010). Pronunciamiento de la CAR. Permiso 026 . Bogotá, Colombia: Corporacon Autonoma Regional de Cundinamarca.

12. Consorcio Gerenciar- D.A.M.A. (2002). Diagnóstico Cerros Orientales. Bogotá: D.A.M.A.

13. Contraloría de Bogotá. (2002). Deterioro de Participación Ciudadana. Bogotá: Contraloría de Bogotá.

14. D.A.M.A. (1994). Agendas Locales Ambientales Localidada 2 Chapinero. Bogotá: D.A.M.A.

15. D.A.M.A. (2002). Plan de Desarrollo Rural Agropecuario y Ambiental. Bogotá: Departamento Administrativo del Medio Ambiente D.A.M.A.

16. D.A.M.A.. - Bachaqueros. (2002) Protocolo Distrital de Restauración Ecológica. Bogotá: D.A.M.A.

17. D.A.M.A., O MANRIQUE. (2004). Guía técnica para la restauración ecológica en áreas con plantaciones forestales exóticas en el Distrito Capital. Bogotá, D.A.M.A.

18. DECRETO 1791 de 1996. (s.f.). por medio del cual se establece el régimen de aprovechamiento forestal. Bogotá, Colombia, Diario Oficial No. 42.894.

19. DECRETO 2811 de 1974. (s.f.). Código Nacional de Recursos Naturales y de Protección del Medio Ambiente. Bogotá, Colombia: Diario Oficial No. 34243.

20. Durán, M. a. (2010). Plan de aprovechamiento, manejo forestal y restauración ecológica por árboles de alto riesgo. Fundación Universitaria Politécnico Grancolombiano. Bogotá, Documento Interno.

21. Fundación estación biológica bachaqueros-D.A.M.A. (1998) Estudio de estructura dinámica y restauración de los ecosistemas altoandinos de las áreas rurales de Santa Fé de Bogotá. Bogotá: D.A.M.A.

22. Herrán, A. Plan de Manejo de los Cerros Orientales. (2001). Bogotá, Car.

23. IGAC. (Febrero de 1998). Aerofotografía. \#165, Vuelo \# SAV 415. Bogotá, Colombia: Instituto Geográfico Agustín Codazzi.

24. IGAC. (Marzo de 1938). Aerofotografías. 2. Bogotá, Colombia, Instituto Geográfico Agustín Codazzi.

25. Informe visita CAR. (1981). Informe Visita Ocular a las Instalaciones del Centro Educativo Politécnico Grancolombiano. Bogotá: Documento Interno.

26. Lema-Tapias, A. (1995). Dosimetría: algunas aproximaciones estadísticas a la medición forestal. Medellín, Colombia: Universidad Nacional de Colombia.

27. Ley 99 de 1993. (s.f.). Por la cual se crea el Ministerio del Medio Ambiente. Se reordena el Sistema Público Encargado de la Gestión y Conservación del Medio Aambiente y los Recursos Naturales Renovables, se organiza el Sistema Nacional Ambiental, Sina y se dictan otras disposiciones. Bogotá, Colombia, Diario Oficial 41146.

28. Mma-Acofore-Oimt. (2000). Guías técnicas para le ordenación y el manejo sostenible de los bosques naturales. Bogotá, MMA-ACOFORE-OIMT.

29. Pérez-Arbeláez, E. (1978). Plantas útiles de Colombia. Bogotá, Litografía Arco. 
30. Plan de Manejo Ambiental Audiencia Car. (2006). Los Cerros Orientales de Bogotá D.C. Patrimonio Cultural y Ambiental del Distrito Capital, la Región y el País. Bogotá, Alcaldía Mayor de Bogotá.

31. Politécnico Grancolombiano - Proyecto de Desarrollo Ltda. (1981). Inventario Forestal y Paisajístico y Proyecto para el Parque Recreacional del Politécnico Grancolombiano. Bogotá, Proyecto de Desarrollo Ltda.

32. Proyecto de Desarrollo Ltda. (1981). Estudio Gerencial de la Cuenca Hidrográfica de la Quebrada Las Delicias. Distrito Especial de Bogotá: Proyectos de Desarrollo Ltda.

33. Proyecto-Contraloría de Bogotá. (2000). Aplicacion y evaluacion de criterios e indicadores para ordenamiento sostenible de los bosques naturales. Bogotá: Contraloria de Bogotá.

34. Radicación Car. (2010). Radicación No. 20101117541. Bogotá: CAR.

35. Resolución 1141 de 2006 Car. (s.f.). Corporación Autónoma Regional de Cundinamarca CAr. por la cual se adopta el Plan de Manejo Ambiental de la Reserva Forestal Protectora de Bosque Oriental de Bogotá y se establecen otras determinaciones. Bogotá, Colombia, Diario Oficial 46252.

36. Suárez-Calderón, J. (2000). Guía técnica para la elaboración de inventarios forestales. Bogotá, Mma -Acofore-Oimt.

37. Wiesner, C., \& Andrade, G. (2004). Formulación de los lineamientos paisajísticos y urbanísticos para el Sistema de Áreas Protegidas de D.C. Bogotá, Secretaría del Medio Ambiente. 